\title{
Impedimetric Dengue Biosensor based on Functionalized Graphene Oxide Wrapped
} Silica Particles

Seon-Ah Jin ${ }^{\mathrm{a}, ~}{ }^{*}$, Shishir Poudyal ${ }^{\mathrm{b}}$, Ernesto E. Marinero ${ }^{\mathrm{a}}$, Richard J. Kuhn ${ }^{\mathrm{b}}$, and Lia A.

\author{
Stanciu $^{\text {a }}$ \\ ${ }^{a}$ School of Materials Engineering, Purdue University, United States \\ ${ }^{\mathrm{b}}$ Department of Biological sciences, Bindley Bioscience Center, Purdue University, United
}

States

*Corresponding author: Jin153@purdue.edu

Tel: 1-765-409-3068 Fax: 1-765-494-1204

\begin{abstract}
A composite of 3-Aminopropyltriethoxysilane (APTES) functionalized graphene oxide (APTES-GO) wrapped on $\mathrm{SiO}_{2}$ particles $\left(\mathrm{SiO}_{2} @\right.$ APTES-GO) was prepared via selfassembly. Transmission electron microscopy (TEM) and ATR-Fourier Transform Infrared spectroscopy (ATR-FTIR) confirmed wrapping of the $\mathrm{SiO}_{2}$ particles by the APTES-GO sheets. An impedimetric biosensor was constructed and used to sensitively detect dengue DNA and dengue RNA via primer hybridization using different oligonucleotide sequences. The results demonstrated that the $\mathrm{SiO}_{2} @$ APTES-GO electrode material led to enhanced dengue RNA detection sensitivity with selectivity and detection limit (1 femto-Molar), compared to both APTES-GO and APTES-SiO 2 . The three-dimensional structure, higher contact area, electrical properties and the ability for rapid hybridization offered by the $\mathrm{SiO}_{2} @$ APTES-GO led to the successful design of a dengue biosensor with the lowest detection limit reported to date.
\end{abstract}

\section{KEYWORDS}

Graphene, Dengue, RNA hybridization, Impedance biosensors 


\section{Introduction}

Dengue fever is one of the most important arthropod-borne viral diseases that can lead to complications such as dengue hemorrhagic fever (DHF) and dengue shock syndrome (DSS), and has the capacity to rapidly spread once a viral outbreak is established [1]. Tropical and subtropical areas in South America, Africa and South-East Asia are especially affected by dengue virus (DENV), which is spread by mosquitoes. Moreover, global warming, intercontinental transportation, and international travel are transforming DENV from a once limited regional problem into a global one [2]. According to the WHO report (World Health Organization), about $40 \%$ of world's populations is at risk of Dengue and it is presently endemic in over 100 countries. The CDC (Center of Disease Control) estimates that as many as 400 million people are infected yearly.

Early diagnosis of dengue is crucial to decreasing medical conditions [3], such as hemorrhage and shock from DHF and DSS, because there is no effective vaccine to prevent the dengue virus infection. A recent large test trial on the CYD-TDV vaccine for dengue did not provide the anticipated results. The vaccine proved to be ineffective, especially for the dengue serotype 2, which was the predominant serotype in the test [4].

Current DENV detection methods rely on complex polymerase chain reaction (PCR) and enzyme-linked immune-sorbent assay (ELISA). However, performing these tests require a high time investment, and meticulous specimen preparation [5,6]. Although the ELISA method is less complicated than PCR, it requires several days between fever symptom emergence and diagnosis because it is based on the detection of immunoglobulin (Ig) in blood. Thus, the test cannot be conducted until either antibodies such as IgM [7] or IgG are produced in response to infection.

Biosensors are bioanalytical tools that measure the presence of analytes by combining the sensitivity of biomolecular recognition elements with a physical transduction mechanism. They play a major role in the development of time-effective, low-cost and easy-to-use analytical tools and are particularly suitable for miniaturization and portability. Their advantages include their high sensitivity and specificity provided by the biocatalytic or biorecognition sensing elements. Various kinds of biosensors (enzyme-based, immunosensors, DNA-sensors) have been broadly studied but only few of them have been successfully commercialized [8].

The biosensors market is expected to grow from $\$ 6.72$ billion in 2009 to $\$ 14.42$ billion in 2016. Most of the developed biosensors address medical needs and are used for diagnostics purposes [8,9]. Applications in environmental and agricultural fields, and particularly for anti-terrorist activity and homeland security, are also rapidly increasing [10,11]. For example, optical biosensors have now the highest sensitivity, approaching 
theoretical limits of interface sensitivity, which is critical for detection of drug candidates, viruses or pathogens [12-16].

Electrochemical biosensors function on the basis of correlating the electronic signal given off upon interaction of the biological recognition element with the analyte. There are different types of electrochemical biosensors, which measure the electrical properties of an electrode surface and the binding kinetics of molecules. In particular, electrochemical impedance spectroscopy (EIS) can measure the changes of the electrical properties of a surface arising from the interaction with the captured analyte [17], while minimizing sample damage during measurements.

Graphene has emerged as a promising candidate material for electrical applications due to its high electrical conductivity, chemical stability, and high mechanical strength $[18,19]$. These characteristics make graphene an attractive material platform for electrochemical biosensor development. Incorporating graphene-based materials in biosensing configurations led to enhanced sensitivity, low detection limits, and long-term stabilities for various types of biosensors $[18,20]$. In particular, graphene has been used for integration in DNA sensing platforms. Graphene sheets functionalized with polyaniline and $\mathrm{Au}$ nano-particles were developed to further enhance electrical conductivity and surface characteristics [21]. CVD-grown graphene-Pt (MPA) nanocomposites were also reported as successful biosensing platforms for the detection of human C-reactive protein [22]. The chemical reactivity and high surface area of graphene allowed for a high loading of $\mathrm{Pt}$ particles, which, in turn, resulted in the attachment of a large number of antibodies, and therefore enhanced sensor performance in the detection of the human C-reactive protein.

Graphene wrapped nanoparticles, on the other hand, exhibited excellent electrochemical performance in batteries and capacitors [23,24], but were rarely explored as a biosensor material. A graphene-encapsulated nanoparticle FET biosensor for cancer biomarker detection was among the few such reports. The detection limit for this sensor was $100 \mathrm{pM}$ target breast cancer biomarkers (HER2) [25].

Here we report on the fabrication of positively charged graphene wrapped particles and their use as sensitive biosensor material platform for dengue DNA and RNA detection. Graphene oxide (GO) sheets were functionalized with 3-Aminopropyltriethoxysilane (APTES) to induce a positive surface charge before coating silica nanoparticles $\left(\mathrm{SiO}_{2}\right)$. Next, the particles were incorporated into an impedimetric biosensor and functionalized with specific primers for the detection of dengue DNA and RNA separately. Sensitivity, selectivity, and detection limits are here reported for the first time for a Dengue biosensor employing this type of electrode material. 


\section{Experimental}

\subsection{Biological elements preparation}

The oligonucleotide primers, dengue complementary DNA, and non-complementary DNA, were purchased from Integrated DNA Technologies, Inc. Serotype 2 Dengue DNA was used as complementary DNA and West Nile virus DNA was used for the source of noncomplementary DNA. An oligonucleotide primer was designed and used as a probe for DNA hybridization and its sequence is 5'-GGT-TGG-ATG-CGC-GCA-TCT-ATT-CTG-ACCCAC-TGG-3'.

The primer for RNA was designed as this sequence 5'-ATA-CAA-TGT-GGC-ATGTCA-CAC-GTG-GCG-3' and Integrated DNA Technologies, Inc. prepared the sequence of primer. The Serotype 2 Dengue RNA was prepared using infected mosquito cell lines by extraction and precipitation. (See supplementary information)

\subsection{Materials synthesis}

Silica particles were synthesized by the modified Stober method [26]: $9.01 \mathrm{ml}$ of DI water, $50 \mathrm{ml}$ of ethanol (100\%, KOPTEC) and $1.37 \mathrm{ml}$ of ammonium hydroxide $\left(\mathrm{NH}_{3}\right.$ $28 \sim 30 \%$, Sigma-Aldrich) were mixed together and $3.2 \mathrm{ml}$ of tetraethyl orthosilicate (TEOS, 99\%, Fluka) was added drop-wise into the mixed solution. After 1 hour, the synthesized particles were separated from the mixed solution using an ultracentrifuge (Eppendorf AG 22331, Hamburg, Germany) spinning at $14.5 \mathrm{krpm}$, and then repeatedly washed using ethanol at least six times. The washed particles were first dried at $80^{\circ} \mathrm{C}$ for 6 hours and then were grinded into fine particles. Subsequently, they were heat-treated in air at $110^{\circ} \mathrm{C}$ for $24 \mathrm{hrs}$. The end product was finally grinded again.

The graphene oxide (GO) sheets were prepared through chemical oxidation of graphite particles by a modified Hummer's method [27]. The oxidized graphene was washed and dried under vacuum environment then finally exfoliated via ultra-sonication.

Positively charged graphene oxide was prepared using 3-Aminopropyltriethoxysilane (APTES, 99\%, Sigma-Aldrich) by the reflux method. $20 \mathrm{mg}$ of GO was first dispersed in 100 $\mathrm{ml}$ of toluene (99.8\%, Sigma-Aldrich). The GO dispersed solution was degassed using nitrogen gas $(99.995 \%)$ for $15 \mathrm{~min}$ to remove oxygen within the solution, then $0.6 \mathrm{ml}$ of APTES was injected into the mixed solution. The solution was stirred for $3 \mathrm{hrs}$ at $30^{\circ} \mathrm{C}$ in a nitrogen atmosphere and then refluxed at $110^{\circ} \mathrm{C}$ for $10 \mathrm{hrs}$ under an inert nitrogen gas environment. The APTES grafted-GO (APTES-GO) was rinsed several times with toluene, ethanol and DI water, using an ultracentrifuge. APTES-grafted $\mathrm{SiO}_{2}$ particles were prepared through the reflux method, similarly to the preparation of APTES-GO. (See supplementary information) 
Each material was dispersed in aqueous solution using $12 \mathrm{mg}$ of APTES-GO, $4 \mathrm{mg}$ of $\mathrm{SiO}_{2}$ particles and DI water separately. The APTES-GO solution was dropped into the $\mathrm{SiO}_{2}$ dispersed solution under ultra-sonication, then stored for $24 \mathrm{hrs}$. The coagulated $\mathrm{SiO}_{2} @$ APTES-GO composite was rinsed using an ultracentrifuge with DI water several times.

\subsection{Materials characterization}

Microstructural observations were performed using a FEI-Tecnai Transmission Electron Microscope (TEM), to confirm the morphology and size of $\mathrm{SiO}_{2}$ particles, as well as the microstructure of the $\mathrm{SiO}_{2} @$ APTES-GO composite. The surface charge was measured using a Malvern Zetasizer (Nano Z, Malvern, UK). We employed 0.02wt\% of material

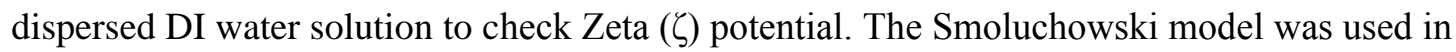
order to convert from the electrophoretic mobility to $\zeta$ potential. The functional groups present before and after self-assembly synthesis of the composite were confirmed via ATRFTIR spectroscopy using a Spectrum 100 FTIR spectrometer (Perkin Elmer, Waltham, MA).

\subsection{Electrochemical characterization}

Biosensor platform was fabricated on a $5 \mathrm{~mm}$ platinum electrode. Functionalized material was dispersed on the Pt electrode than primer was immobilized on the material coated electrode that finally incubated in DNA or RNA solution for hybridization. A platinum electrode was first cleaned by polishing with alumina paste and washing by sonication with DI and ethanol solution, and subsequently used for biosensor platform fabrication. A concentration of 0.2 wt. $\%$ of the positively functionalized material (APTES-SiO ${ }_{2}$, APTESGO, and $\mathrm{SiO}_{2} @$ APTES-GO) solution was prepared using DI water. A volume of $20 \mathrm{ul}$ of the mixture was dropped on the Pt electrode, and then unadsorbed materials were removed by washing with DI water after $10 \mathrm{~min}$. The primer was immobilized on the positively functionalized material layer at room temperature; excessive primers that were not successfully immobilized were removed after primer immobilization, 40 minutes for DNA target and $2 \mathrm{hrs}$ for RNA target separately, through rinsing with DI water. The electrodes were incubated with various concentrations $(10 \mathrm{pM}, 1 \mathrm{fM}$, and $1 \mathrm{aM})$ of complementary DNA and $10 \mathrm{pM}$ non-complementary DNA in a $10 \mathrm{mM}$ PBS solution at $60^{\circ} \mathrm{C}$ for 5 hrs. Finally, the electrodes were washed with DI water to remove unhybridized DNA. RNA hybridization was separately conducted under same conditions with that of DNA hybridization under the various concentration of RNA in RNase free water.

Electrochemical impedance spectroscopy (EIS) was performed in $10 \mathrm{mM}$ PBS containing $10 \mathrm{mM} \mathrm{K}_{4}\left[\mathrm{Fe}(\mathrm{CN})_{6}\right]^{4-} / \mathrm{K}_{3}\left[\mathrm{Fe}(\mathrm{CN})_{6}\right]^{3-}$ electrolyte using a Biologic potentiostat (SP-150, Bio-Logic SAS, France). A three-electrode electrochemical cell for EIS analysis was prepared with the as-fabricated biosensor electrode as a working electrode, a Pt wire counter 
electrode, and an $\mathrm{Ag} / \mathrm{AgCl}$ reference electrode. Impedance spectra were recorded in the frequency range of $100 \mathrm{mHz}$ to $100 \mathrm{kHz}$, with $10 \mathrm{mV}$ amplitude at open circuit voltage(OCV). Using the impedance data, the charge-transfer resistance ( $\left.\mathrm{R}_{\mathrm{CT}-\text {-layer }}\right)$ of APTES-SiO${ }_{2}$, APTES$\mathrm{GO}$, and $\mathrm{SiO}_{2} @$ APTES-GO, respectively, of a immobilized primer layer $\left(\mathrm{R}_{\mathrm{CT} \text {-primer }}\right)$, and of a hybridized complementary DNA or RNA layer $\left(\mathrm{R}_{\text {Ст-Сом }}\right)$ were analyzed using the Randles' model [28].

\section{Results and discussion}

The positively charged APTES molecules were grafted on $\mathrm{SiO}_{2}$ particles and GO sheets to facilitate immobilization of negatively charged dengue primers for dengue DNA or RNA target on the surface of each material. The surface charge of each individual material component was determined through $\zeta$ potential measurements before the self-assembly process of the composite material. All the APTES included samples, APTES-SiO 2 , APTESGO, and $\mathrm{SiO}_{2} @$ APTES-GO, clearly showed positive surface charge values; the $\zeta$ potential of $\mathrm{SiO}_{2}$ particles was $-34.7 \mathrm{mV}$ and it changed to a positive potential of $+29.9 \mathrm{mV}$ after the reflux with APTES, while that of $\mathrm{GO}$ was $-43.3 \mathrm{mV}$, changing to $+24.4 \mathrm{mV}$ after reflux treatment (Fig. 1). These changes in the $\zeta$ potential showed that the APTES molecules were successfully anchored on the surface of these materials.

The APTES-GO sheets and $\mathrm{SiO}_{2}$ particles were used towards the self-assembly of the $\mathrm{SiO}_{2} @$ APTES-GO composite. The driving force for the self-assembly process is the electrostatic attraction between the two components. Opposite charges and an adequate $\zeta$ potential gap are necessary for a successful self-assembly process. The $\mathrm{SiO}_{2}$ particles display a negative charge $(-34.7 \mathrm{mV})$ while the APTES-GO sheets have a positive charge (+24.4 mV), leading to self-assembly through electrostatic interaction. The $\zeta$ potential gap between these components is $59.1 \mathrm{mV}$, which, based on literature values, is sufficient for the self-assembly process to proceed [29,30]. Hu et al. [29] reported on the successful self-assembly of graphene-metal oxide composites with a $53.3 \mathrm{mV} \zeta$ potential gap between $\mathrm{TiO}_{2}$ nanosol and reduced GO nanosheets.

The microstructure of $\mathrm{SiO}_{2}$ particles and $\mathrm{SiO}_{2} @$ APTES-GO composites were evaluated through TEM analysis. The $\mathrm{SiO}_{2}$ particles were synthesized through a modified Stober method, and Fig. 2(a) clearly shows spherically shaped $\mathrm{SiO}_{2}$ particles. The $\mathrm{SiO}_{2}$ particle size and particle size distribution was extracted from several TEM images using the ImageJ software (not shown here). The results indicate a uniform size distribution, and an average particle size of $206 \mathrm{~nm}$. TEM also confirmed that the APTES-GO sheets successfully covered the $\mathrm{SiO}_{2}$ particles. Fig. 2 (b) shows the morphology of the $\mathrm{SiO}_{2} @$ APTES-GO composite, including the wrapping of the functionalized GO around the silica particles. Moreover this composite showed a positive value of the $\zeta$ potential $(+16.7 \mathrm{mV})$, which 
suggests the presence of positive functional groups on the surface of composite material that are further available for electrostatic interaction with the negatively charged oligonucleotide primers (Fig 1).

Attenuated Total Reflectance Fourier Transform Infrared (ATR-FTIR) spectroscopy was performed to confirm the presence of APTES in the APTES-GO and $\mathrm{SiO}_{2} @$ APTES-GO samples. Fig. 3 shows the ATR-FTIR spectra of each $\mathrm{SiO}_{2}$ particles, APTES-GO sheets, and their composite, $\mathrm{SiO}_{2} @$ APTES-GO. The peak at $1602 \mathrm{~cm}^{-1}$ appeared after the self-assembly process of $\mathrm{SiO}_{2} @$ APTES-GO, it is observed in all APTES containing samples, and can be attributed to the presence of the $\mathrm{N}-\mathrm{H}$ bending vibration from the amine groups in APTES. Ou et al [31] reported the presence of a large peak at $1652 \mathrm{~cm}^{-1}$, which was observed when a sample containing the Zwitter ionic-bond of the amine group interacted with the anionic carboxyl group of GO. However, a peak representative of a Zwitter ionic-bond was not observed in our results for any APTES-containing samples. This suggests that the main functional group of all the positively charged materials, i.e. APTES-GO, APTES-SiO $\mathrm{SiO}_{2} @$ APTES-GO, is an amine group.

Fig. 4 shows the results of impedance spectroscopy measurement for the $\mathrm{SiO}_{2} @$ APTES-GO composite, as well as for $\mathrm{SiO}_{2}$ and APTES-GO. All the impedance data were analyzed using an equivalent Randles circuit, and the interfacial charge transfer resistance $\left(\Delta R_{C T}\right)$ of each layer $\left(R_{C T-l a y e r}\right)$ was calculated from subtracting $R_{C T}$ of the bare $P t$ electrode from the $\mathrm{R}_{\mathrm{CT}}$ of the coated electrode with APTES-GO, APTES-SiO $\mathrm{S}_{2}$, and $\mathrm{SiO}_{2} @$ APTES-GO, respectively. The $\mathrm{R}_{\mathrm{CT}}$ of the bare Pt electrode was evaluated for every experiment and the average value was $8.9 \pm 1.25 \Omega$ The calculated $\mathrm{R}_{\mathrm{CT} \text {-layer }}$ values for APTESGO, $\mathrm{SiO}_{2}$, APTES-SiO ${ }_{2}$, and $\mathrm{SiO}_{2} @$ APTES-GO were $2.91 \pm 0.4 \Omega, 3.67 \pm 0.6 \Omega, 3.76 \pm 0.5 \Omega$, and $2.72 \pm 0.4 \Omega$ respectively. The interfacial $\mathrm{R}_{\mathrm{CT}}$ in the APTES-GO and $\mathrm{SiO}_{2} @$ APTES-GO systems was observed to be lower than that of bare $\mathrm{SiO}_{2}$ particles. Despite the higher resistance of the silica core, the $\mathrm{SiO}_{2} @$ APTES-GO has a measured interfacial $\mathrm{R}_{\mathrm{CT}}$ as low as the one for APTES-GO. This indicates that the resistance of the graphene oxide dominates the interfacial $\mathrm{R}_{\mathrm{CT}}$ of $\mathrm{SiO}_{2}$ @APTES-GO, which is in good agreement with other reports in the literatures [32,33]. These results are also an indirect indication of the good coating of $\mathrm{SiO}_{2}$ particles with APTES-GO sheets.

The amine functional group in APTES-GO, APTES-SiO 2 , and $\mathrm{SiO}_{2} @$ APTES-GO has the ability to bond to the negatively charged oligonucleotide primers and immobilize it on the electrode. Subsequently, the immobilized primer binds to the dengue complementary DNA or RNA target through hybridization, thus confirming the presence of dengue in the analyte. Although this process seems straightforward, if the electrode is not saturated with primer, false positive results are possible due to the capacity of the amine group from APTES-GO, APTES-SiO ${ }_{2}$, and $\mathrm{SiO}_{2} @$ APTES-GO to bind to any negatively charged molecules, including 
non-complementary DNA. To eliminate this challenge, a non-complementary DNA hybridization test was performed using APTES-SiO ${ }_{2}$ to observe whether the degree of saturation with primer, and hence selectivity, depends on the time of the primer immobilization (Fig. S1).

The interfacial $\mathrm{R}_{\mathrm{CT}}$ of the non-complementary DNA that was hybridized on the electrode was calculated from the impedance results before and after non-complementary DNA hybridization on the coated layer of primer immobilized APTES-SiO ${ }_{2}$ electrodes. A positive interfacial $R_{C T}$ would result from the non-complementary DNA binding with the amine groups on the surface of APTES-SiO ${ }_{2}$. Non-complementary DNA was bound to the APTES-SiO ${ }_{2}$ after 10 minutes of primer immobilization, as indicated by the increase in the interfacial $\mathrm{R}_{\mathrm{CT}}$ after non-complementary DNA hybridization. As the primer immobilization time progressively increased to 40 minutes, the interfacial $R_{C T}$ values decreased. Thus, it was confirmed that 40 minutes of primer immobilization time are necessary for full coverage of the amine groups on APTES-SiO 2 .

The dependence of temperature for complementary DNA hybridization of APTES$\mathrm{SiO}_{2}$ was also investigated, in an effort to optimize a DNA hybridization conditions for the primer sequence. Generally, DNA hybridization is performed at higher than room temperature for polymerase chain reaction (PCR), and the way the aging temperature is selected dependent on the primer sequence. Moreover, previous reports showed a wide temperature range for dengue DNA hybridization. Andul et al. [34] and Deng et al. [35] hybridized dengue DNA at room temperature, while Nascimento et al. [36] performed the same experiments at $40^{\circ} \mathrm{C}$, and Rai et al. [5] tested at $45^{\circ} \mathrm{C}$ for serotype 2 DNA detection. We tested the hybridization of dengue DNA at different temperatures to reveal the optimum conditions of our primer for a shorter sensor response time (Fig. S2). The interfacial $R_{C T}$ of the hybridized complementary DNA ( $\mathrm{R}_{\text {Ст-сом }}$ ) was also calculated from impedance results before and after $5 \mathrm{hrs}$ of DNA hybridization. The $\mathrm{R}_{\text {Ст-сом }}$ increased up to $60^{\circ} \mathrm{C}$, which was observed to be the temperature for the maximum measured resistance. Further increasing the

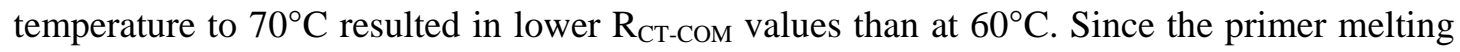
temperature is $85^{\circ} \mathrm{C}$, we attribute the decrease in $\mathrm{R}_{\mathrm{CT}-\mathrm{COM}}$ at $70^{\circ} \mathrm{C}$ to the fact that this temperature is rather close to the melting temperature, it may result in some degradation. We conclude that an increase in temperature generally results in an acceleration of dengue DNA hybridization up to a maximum temperature of $60^{\circ} \mathrm{C}$.

The $60^{\circ} \mathrm{C}$ temperature, and five hours hybridization time were subsequently used for all experiments. Every DNA and RNA hybridization test was repeated three times and all the reported interfacial resistance values from the hybridized target onto the electrode represent the average value of the data (Fig 5, S2, and S3a,b). To understand the effect of particle morphology on the hybridization performance the behavior of each of these positively 
charged materials, the APTES-GO, APTES-SiO ${ }_{2}$, and $\mathrm{SiO}_{2} @$ APTES-GO, during complementary DNA hybridization were compared to each other. Each electrode material was exposed to a concentration of $10 \mathrm{pM}$ dengue complementary DNA. Fig. 5 depicts each of the three electrodes' measured interfacial charge-transfer resistance, $\mathrm{R}_{\mathrm{CT}-\mathrm{COM}}$, upon DNA hybridization. The $\mathrm{R}_{\text {CT-сом }}$ values for APTES-GO, APTES-SiO ${ }_{2}$, and $\mathrm{SiO}_{2} @$ APTES-GO were $6.37 \pm 1.97 \Omega, 22.22 \pm 1.7 \Omega$, and $33.29 \pm 1.24 \Omega$, respectively. It is apparent that APTESGO had the lowest interfacial $\mathrm{R}_{\mathrm{CT}}$ upon complementary DNA hybridization, while APTES$\mathrm{SiO}_{2}$ showed a higher interfacial $\mathrm{R}_{\mathrm{CT}}$ value than APTES-GO. This could be an indication of the advantage that the increased contact area between target solution and electrode surface stemming from the spherical morphology of the silica particles confers to complementary DNA hybridization. The increased contact area was confirmed by a larger double-layer capacitance of the 3-dimensional structure $\left(20.38 \pm 1.01 \mathrm{uF} / \mathrm{cm}^{2}, \mathrm{SiO}_{2} @\right.$ APTES-GO) than that of the 2-dimensional structure $\left(16.43 \pm 0.99 \mathrm{uF} / \mathrm{cm}^{2}\right.$, APTES-GO). This automatically leads to an enhancement of sensitivity and a lower detection limit for the biosensor. At the same time, it is to be noted that $\mathrm{SiO}_{2} @$ APTES-GO showed a higher average interfacial $\mathrm{R}_{\mathrm{CT}}$ of hybridized complementary DNA than both APTES-GO, and APTES-SiO ${ }_{2}$, rendering $\mathrm{SiO}_{2} @$ APTES-GO as the most effective electrode material for the sensitive detection of dengue.

The DNA hybridization results were converted to the relative value to allow a direct comparison to the results of a recently reported dengue DNA impedimetric sensor based on AuNpPANI particles [36]. The relative value $\left(\Delta \mathrm{R}_{\mathrm{CT}} \%\right)$ was calculated using the value of interfacial $\mathrm{R}_{\mathrm{CT}}$ of the hybridized target divided by $\mathrm{R}_{\mathrm{CT}}$ value before the hybridization of the biosensor platform, which is the same equation used by Nascimento et al [36]. According to this previous report, the AuNpPANI particles showed a change of $87.5 \%$ of $\Delta \mathrm{R}_{\mathrm{CT}} \%$, upon the detection of $10 \mathrm{pM}$ dengue DNA. In our work, the $\Delta \mathrm{R}_{\mathrm{CT}} \%$ values obtained upon $10 \mathrm{pM}$ DNA hybridization of APTES-SiO $\mathrm{S}_{2}$ and $\mathrm{SiO}_{2} @$ APTES-GO composite were 120.4\% and 223.4\%, respectively. Our graphene oxide coated silica spherical particles with a $206 \mathrm{~nm}$ diameter were more sensitive than AuNpPANI particles and our composite showed more than twice the sensitivity value due to the decreased electron-transfer resistance resulting from the APTES-GO coated on the $\mathrm{SiO}_{2}$ particles and enhanced hybridization ability of the functionalized composite.

Selectivity of $\mathrm{SiO}_{2} @$ APTES-GO was also tested in this work (Fig. 6, and Fig S3-a). The primer immobilized $\mathrm{SiO}_{2} @$ APTES-GO selectively hybridized with the target complementary DNA. The interfacial $\mathrm{R}_{\mathrm{CT}}$ upon non-complementary DNA hybridization was $2.34 \pm 4.56 \Omega$ a value below the error range while the interfacial $R_{C T}$ from DNA hybridization using $1 \mathrm{fM}$ complementary DNA solution was $26.87 \pm 5.79 \Omega$. Thus, we can state with confidence that the primer immobilized on $\mathrm{SiO}_{2} @$ APTES-GO was effective in selectively hybridizing dengue DNA. 
The dengue complementary RNA hybridization was performed using oligonucleotide primer for dengue serotype 2 RNA to verify the RNA sensing ability of the electrode materials. The materials showed the same sensitivity trends as for DNA hybridization. Fig. 7, and $\mathrm{S} 3$ (b) shows the results of the RNA hybridization for $10 \mathrm{pM}$ and $1 \mathrm{fM}$ for APTES- $\mathrm{SiO}_{2}$ and $\mathrm{SiO}_{2} @$ APTES-GO. SiO $\mathrm{S}_{2} @$ APTES-GO clearly showed a higher RNA hybridization sensitivity than APTES-SiO $\mathrm{S}_{2}$ as well as the DNA hybridization (Fig 7). The average $\mathrm{R}_{\text {CT-COM }}$ values measured upon 10pM RNA hybridization were $33.11 \pm 11.09 \Omega$ for APTES- $\mathrm{SiO}_{2}$, and $52.81 \pm 6.25 \Omega$ for $\mathrm{SiO}_{2} @$ APTES-GO, respectively. All the values measured for RNA hybridization at same concentration condition are larger than those for DNA hybridization, which may be due to the longer RNA sequence than DNA and knot-like structure of RNA. It is possible that the larger size and more tightly folded structure of RNA can inhibit the charge transfer at the electrode surface to a higher extent than DNA, which is smaller and has a more of a linear structure.

Further experiments were performed to determine the limit of detection (LOD) of the $\mathrm{SiO}_{2} @$ APTES-GO based dengue biosensor. Thus, the complementary dengue DNA solution was diluted to 1 femto-molar concentration and subsequently exposed to the electrode material for hybridization. The results (Fig. S3a) show slightly lower interfacial $\mathrm{R}_{\mathrm{CT}}$ value of $\mathrm{SiO}_{2} @$ APTES-GO to for the $10 \mathrm{pM}$ dengue DNA solution, proving that the biosensor is capable to detect dengue at concentration levels as low as 1 femto-molar. We can thus state that it is likely that all primer molecules immobilized on $\mathrm{SiO}_{2} @$ APTES-GO were hybridized with the complementary DNA down to a $1 \mathrm{fM}$ concentration under the reaction conditions. The LOD of RNA hybridization was also observed using 1 fM RNA solution (Fig 7 and Fig $\mathrm{S} 3 \mathrm{~b}$ ). The interfacial $\mathrm{R}_{\text {СT-сом }}$ value of $\mathrm{SiO}_{2} @$ APTES-GO showed similar hybridization ability regardless of the RNA concentration. Fig. S3b shows the interfacial $\mathrm{R}_{\text {Ст-сом value of }}$ $\mathrm{SiO}_{2} @$ APTES-GO for 1fM RNA hybridization, which was similar $(48.91 \pm 4.47 \Omega)$ to the value for $10 \mathrm{pM}$ RNA hybridization $(52.81 \pm 6.25 \Omega)$. In this sense, the $\mathrm{R}_{\text {Ст-Сом }}$ values upon dengue DNA and RNA hybridization in a $1 \mathrm{fM}$ concentration target DNA or RNA were three times above noise level (standard error), suggesting that even lower concentrations of dengue could be detected by this system. To the best of our knowledge, this is the lowest reported LOD for a label-free electro-chemical biosensor for dengue DNA and RNA detection [37-39].

The superior performance of $\mathrm{SiO}_{2} @$ APTES-GO compared to APTES-GO and APTES-SiO ${ }_{2}$ in terms of selectivity, sensitivity and detection limit is attributed to the synergistic effect of the higher contact area of the spherical morphology, combined with the electronic properties of GO [24]. It is now a well-known fact that functionalized graphene/graphene oxide materials display high electro-catalytic activity owing to a fast electron transfer rate when these materials are employed in such systems. 


\section{Conclusions}

In summary, a functionalized graphene oxide wrapped $\mathrm{SiO}_{2}$ particle composite has been successfully developed for the design of a sensitive impedimetric biosensor for dengue DNA and RNA. TEM, FT-IR spectra, and impedance results successfully proved the effectiveness of the synthesis procedure towards wrapping of the $\mathrm{SiO}_{2}$ particles with APTESfunctionalized GO sheets. The impedance data indicated that $\mathrm{SiO}_{2} @$ APTES-GO was an excellent electrode material for each dengue DNA and RNA using different primer for each target, resulting in superior selectivity and a dengue detection limit below $1 \mathrm{fM}$. The high contact area and fast electron transfer capabilities make $\mathrm{SiO}_{2} @ \mathrm{APTES}-\mathrm{GO}$ a promising electrode material platform to be transferred towards the fabrication of other electrochemical based biosensing systems.

\section{Acknowledgements}

The authors are grateful for the financial support provided by the National Science Foundation DMR \#0804464, as well as for the support provided by ICTSI Purdue Project Development Team within the ICTSI NIH/NCRR (Grant Number UL1TR001108). 


\section{References}

[1] M.G. Guzman, E. Harris, Dengue, The Lancet. 385 (2015) 453-465. doi:10.1016/S0140-6736(14)60572-9.

[2] A. Wilder-Smith, D.J. Gubler, Geographic Expansion of Dengue: The Impact of International Travel, Med. Clin. North Am. 92 (2008) 1377-1390. doi:10.1016/j.mena.2008.07.002.

[3] S. Idrees, U.A. Ashfaq, A brief review on dengue molecular virology, diagnosis, treatment and prevalence in Pakistan, Genet. Vaccines Ther. 10 (2012) 1-10. doi:10.1186/1479-0556-10-6.

[4] A. Sabchareon, D. Wallace, C. Sirivichayakul, K. Limkittikul, P. Chanthavanich, S. Suvannadabba, et al., Protective efficacy of the recombinant, live-attenuated, CYD tetravalent dengue vaccine in Thai schoolchildren: a randomised, controlled phase $2 b$ trial, The Lancet. 380 (2012) 1559-1567. doi:10.1016/S0140-6736(12)61428-7.

[5] V. Rai, H.C. Hapuarachchi, L.C. Ng, S.H. Soh, Y.S. Leo, C.-S. Toh, Ultrasensitive cDNA Detection of Dengue Virus RNA Using Electrochemical Nanoporous Membrane-Based Biosensor, PLoS ONE. 7 (2012) e42346. doi:10.1371/journal.pone.0042346.

[6] S. Xu, Electromechanical biosensors for pathogen detection, Microchim. Acta. 178 (2012) 245-260. doi:10.1007/s00604-012-0831-4.

[7] M.G. Guzman, S. Vázquez, G. Kouri, Dengue: where are we today?, Malays. J. Med. Sci. MJMS. 16 (2009) 4-11.

[8] N.J. Forrow, S.W. Bayliff, A commercial whole blood glucose biosensor with a low sensitivity to hematocrit based on an impregnated porous carbon electrode, Biosens. Bioelectron. 21 (2005) 581-587. doi:10.1016/j.bios.2004.12.011.

[9] N.J. Forrow, G.S. Sanghera, S.J. Walters, J.L. Watkin, Development of a commercial amperometric biosensor electrode for the ketone d-3-hydroxybutyrate, Biosens. Bioelectron. 20 (2005) 1617-1625. doi:10.1016/j.bios.2004.07.009.

[10] F. Long, A. Zhu, H. Shi, Recent Advances in Optical Biosensors for Environmental Monitoring and Early Warning, Sensors. 13 (2013) 13928-13948. doi:10.3390/s131013928.

[11] W. Zhang, A.M. Asiri, D. Liu, D. Du, Y. Lin, Nanomaterial-based biosensors for environmental and biological monitoring of organophosphorus pesticides and nerve agents, TrAC Trends Anal. Chem. 54 (2014) 1-10. doi:10.1016/j.trac.2013.10.007.

[12] H. Ahmadi, H. Heidarzadeh, A. Taghipour, A. Rostami, H. Baghban, M. Dolatyari, et al., Evaluation of single virus detection through optical biosensor based on microsphere resonator, Opt. - Int. J. Light Electron Opt. 125 (2014) 3599-3602. doi:10.1016/j.ijleo.2014.01.087.

[13] Z.B. Bahşi, A. Büyükaksoy, S.M. Ölmezcan, F. Şimşek, M.H. Aslan, A.Y. Oral, A Novel Label-Free Optical Biosensor Using Synthetic Oligonucleotides from E. coli O157:H7: Elementary Sensitivity Tests, Sensors. 9 (2009) 4890-4900. doi:10.3390/s90604890.

[14] D.G. Bracewell, R.A. Brown, M. Hoare, Addressing a whole bioprocess in real-time using an optical biosensor-formation, recovery and purification of antibody fragments from a recombinant E. coli host, Bioprocess Biosyst. Eng. 26 (2004) 271-282. doi:10.1007/s00449-004-0359-z.

[15] R.C. Stringer, S. Schommer, D. Hoehn, S.A. Grant, Development of an optical biosensor using gold nanoparticles and quantum dots for the detection of Porcine Reproductive and Respiratory Syndrome Virus, Sens. Actuators B Chem. 134 (2008) 427-431. doi:10.1016/j.snb.2008.05.018.

[16] R. Yan, N.S. Lynn, L.C. Kingry, Z. Yi, T. Erickson, R.A. Slayden, et al., Detection of virus-like nanoparticles via scattering using a chip-scale optical biosensor, Appl. Phys. Lett. 101 (2012) 161111. doi:10.1063/1.4758294. 
[17] T. Rinken, ed., State of the Art in Biosensors - General Aspects, InTech, 2013. http://www.intechopen.com/books/state-of-the-art-in-biosensors-general-aspects (accessed November 25, 2014).

[18] T. Kuila, S. Bose, P. Khanra, A.K. Mishra, N.H. Kim, J.H. Lee, Recent advances in graphene-based biosensors, Biosens. Bioelectron. 26 (2011) 4637-4648. doi:10.1016/j.bios.2011.05.039.

[19] S. Stankovich, D.A. Dikin, G.H.B. Dommett, K.M. Kohlhaas, E.J. Zimney, E.A. Stach, et al., Graphene-based composite materials, Nature. 442 (2006) 282-286. doi:10.1038/nature04969.

[20] C.-H. Lu, H.-H. Yang, C.-L. Zhu, X. Chen, G.-N. Chen, A Graphene Platform for Sensing Biomolecules, Angew. Chem. Int. Ed. 48 (2009) 4785-4787. doi:10.1002/anie.200901479.

[21] L. Wang, E. Hua, M. Liang, C. Ma, Z. Liu, S. Sheng, et al., Graphene sheets, polyaniline and AuNPs based DNA sensor for electrochemical determination of BCR/ABL fusion gene with functional hairpin probe, Biosens. Bioelectron. 51 (2014) 201-207. doi:10.1016/j.bios.2013.07.049.

[22] S. Singal, A.M. Biradar, A. Mulchandani, Rajesh, Ultrasensitive Electrochemical Immunosensor Based on Pt Nanoparticle-Graphene Composite, Appl. Biochem. Biotechnol. (2014) 1-13. doi:10.1007/s12010-014-0933-Z.

[23] X. Feng, N. Chen, Y. Zhang, Z. Yan, X. Liu, Y. Ma, et al., The self-assembly of shape controlled functionalized graphene- $\mathrm{MnO} 2$ composites for application as supercapacitors, J. Mater. Chem. A. 2 (2014) 9178. doi:10.1039/c3ta15402e.

[24] Z.-S. Wu, G. Zhou, L.-C. Yin, W. Ren, F. Li, H.-M. Cheng, Graphene/metal oxide composite electrode materials for energy storage, Nano Energy. 1 (2012) 107-131. doi:10.1016/j.nanoen.2011.11.001.

[25] S. Myung, A. Solanki, C. Kim, J. Park, K.S. Kim, K.-B. Lee, Graphene-Encapsulated Nanoparticle-Based Biosensor for the Selective Detection of Cancer Biomarkers, Adv. Mater. 23 (2011) 2221-2225. doi:10.1002/adma.201100014.

[26] X. Lei, B. Yu, H.-L. Cong, C. Tian, Y.-Z. Wang, Q.-B. Wang, et al., Synthesis of Monodisperse Silica Microspheres by a Modified Stöber Method, Integr. Ferroelectr. 154 (2014) 142-146. doi:10.1080/10584587.2014.904651.

[27] W.S. Hummers, R.E. Offeman, Preparation of Graphitic Oxide, J. Am. Chem. Soc. 80 (1958) 1339-1339. doi:10.1021/ja01539a017.

[28] J.V. Rushworth, N.A. Hirst, Impedimetric Biosensors for Medical Applications: Current Progress and Challenges, Momentum Press, 2013.

[29] C. Hu, T. Lu, F. Chen, R. Zhang, A brief review of graphene-metal oxide composites synthesis and applications in photocatalysis, J. Chin. Adv. Mater. Soc. 1 (2013) 21-39. doi:10.1080/22243682.2013.771917.

[30] H. Sun, X. Sun, T. Hu, M. Yu, F. Lu, J. Lian, Graphene-Wrapped Mesoporous Cobalt Oxide Hollow Spheres Anode for High-Rate and Long-Life Lithium Ion Batteries, J. Phys. Chem. C. 118 (2014) 2263-2272. doi:10.1021/jp408021m.

[31] J. Ou, J. Wang, S. Liu, B. Mu, J. Ren, H. Wang, et al., Tribology Study of Reduced Graphene Oxide Sheets on Silicon Substrate Synthesized via Covalent Assembly, Langmuir. 26 (2010) 15830-15836. doi:10.1021/la102862d.

[32] Z.-F. Li, H. Zhang, Q. Liu, Y. Liu, L. Stanciu, J. Xie, Novel Pyrolyzed PolyanilineGrafted Silicon Nanoparticles Encapsulated in Graphene Sheets As Li-Ion Battery Anodes, ACS Appl. Mater. Interfaces. 6 (2014) 5996-6002. doi:10.1021/am501239r.

[33] D. Wei, J. Liang, Y. Zhu, Z. Yuan, N. Li, Y. Qian, Formation of Graphene-Wrapped Nanocrystals at Room Temperature through the Colloidal Coagulation Effect, Part. Part. Syst. Charact. 30 (2013) 143-147. doi:10.1002/ppsc.201200120.

[34] S. Abdul Rahman, R. Saadun, N.E. Azmi, N. Ariffin, J. Abdullah, N.A. Yusof, et al., Label-Free Dengue Detection Utilizing PNA/DNA Hybridization Based on the Aggregation Process of Unmodified Gold Nanoparticles, J. Nanomater. 2014 (2014) e839286. doi:10.1155/2014/839286. 
[35] J. Deng, C.-S. Toh, Impedimetric DNA Biosensor Based on a Nanoporous Alumina Membrane for the Detection of the Specific Oligonucleotide Sequence of Dengue Virus, Sensors. 13 (2013) 7774-7785. doi:10.3390/s130607774.

[36] H.P.O. Nascimento, M.D.L. Oliveira, C.P. de Melo, G.J.L. Silva, M.T. Cordeiro, C.A.S. Andrade, An impedimetric biosensor for detection of dengue serotype at picomolar concentration based on gold nanoparticles-polyaniline hybrid composites, Colloids Surf. B Biointerfaces. 86 (2011) 414-419. doi:10.1016/j.colsurfb.2011.04.028.

[37] F.S.R.R. Teles, Biosensors and rapid diagnostic tests on the frontier between analytical and clinical chemistry for biomolecular diagnosis of dengue disease: A review, Anal. Chim. Acta. 687 (2011) 28-42. doi:10.1016/j.aca.2010.12.011.

[38] F.R.R. Teles, L.P. Fonseca, Trends in DNA biosensors, Talanta. 77 (2008) 606-623. doi:10.1016/j.talanta.2008.07.024.

[39] M.S. Cheng, C.-S. Toh, Novel biosensing methodologies for ultrasensitive detection of viruses, Analyst. 138 (2013) 6219-6229. doi:10.1039/C3AN01394D. 


\section{Figure captions}

Fig. $1 \zeta$ potential distribution of (a) $\mathrm{SiO}_{2}$, (b) APTES- $\mathrm{SiO}_{2}$, (c) GO, (d) APTES-GO, and (e) $\mathrm{SiO}_{2} @$ APTES-GO composite

Fig. 2 TEM image of as-prepared (a) $\mathrm{SiO}_{2}$ particle, and (b) $\mathrm{SiO}_{2} @$ APTES-GO composite Fig. 3 FTIR spectra of (a) $\mathrm{SiO}_{2}$, (b) APTES-GO, and (c) $\mathrm{SiO}_{2} @$ APTES-GO composite Fig. 4 Nyquist impedance plot of (a) $\mathrm{SiO}_{2}$ (b) APTES-GO, and (c) $\mathrm{SiO}_{2} @$ APTES-GO composite

Fig. 5 Interfacial charge-transfer resistance from hybridized complementary DNA ( $\mathrm{R}_{\text {Ст-сом}}$ ) of (a) APTES-GO, (b) APTES-SiO ${ }_{2}$, and (c) $\mathrm{SiO}_{2} @$ APTES-GO composite

Fig. 6 Nyquist impedance plot of $\mathrm{SiO}_{2} @$ APTES-GO composite before and after (a) 10 pM non-complementary DNA hybridization, (b) $1 \mathrm{fM}$ complementary DNA hybridization Fig. 7 Nyquist impedance plot of (a) before and after $1 \mathrm{fM}$ RNA hybridization of APTES$\mathrm{SiO}_{2}$, (b) before and after $1 \mathrm{fM}$ complementary RNA hybridization of $\mathrm{SiO}_{2} @$ APTES-GO composite 


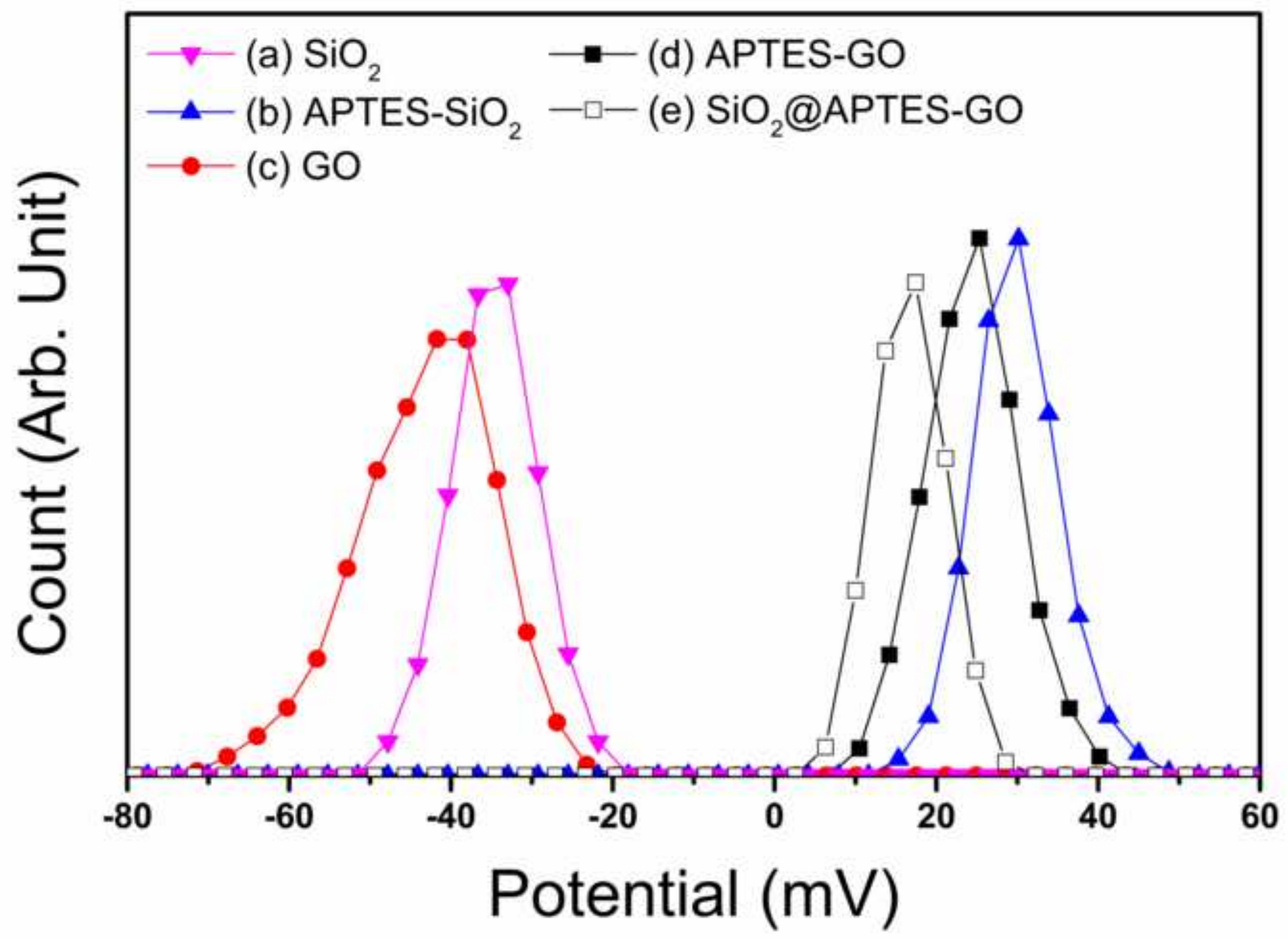


Figure 2a

(a)

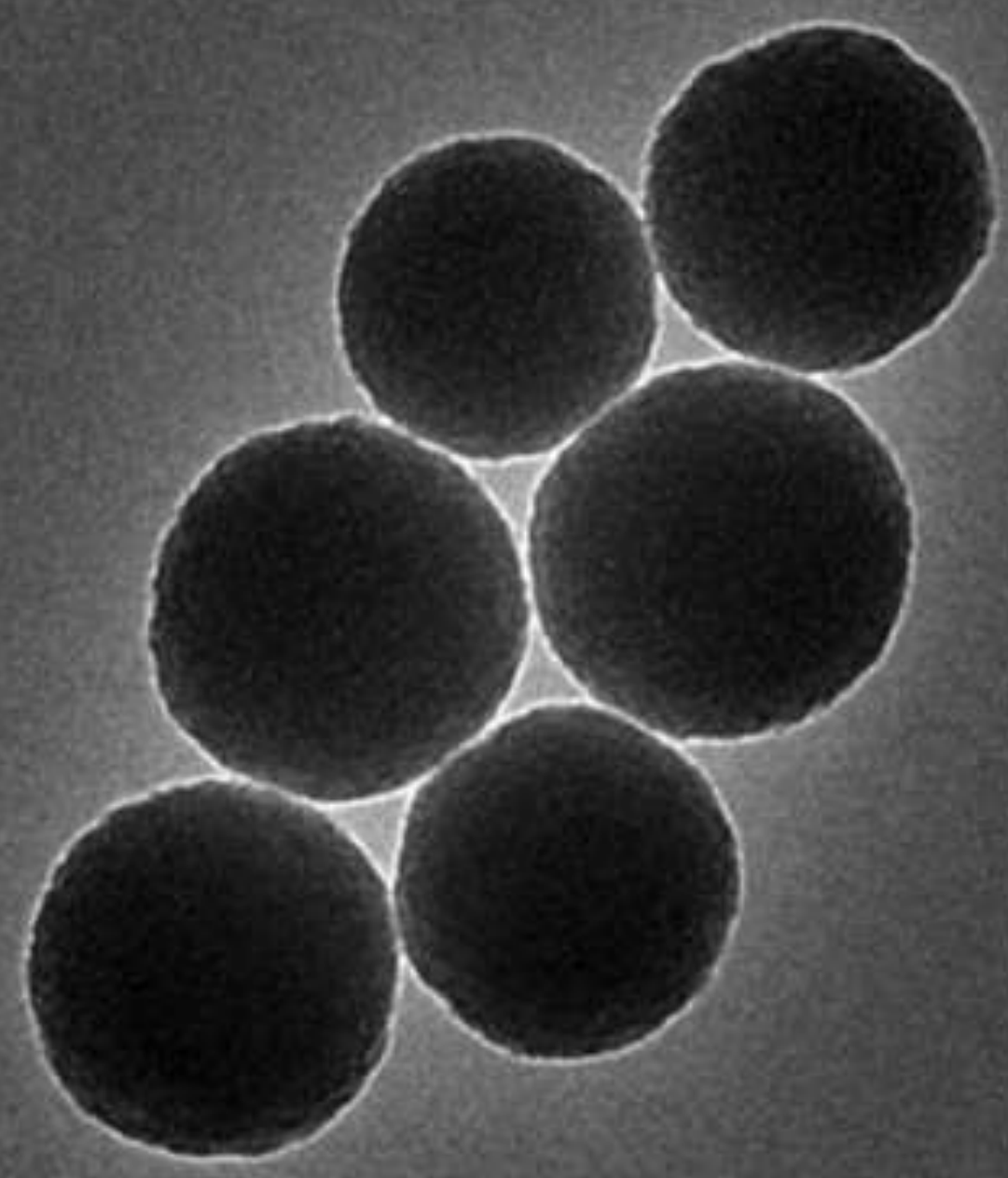

$100 \mathrm{~nm}$ 
(b)

$100 \mathrm{~nm}$

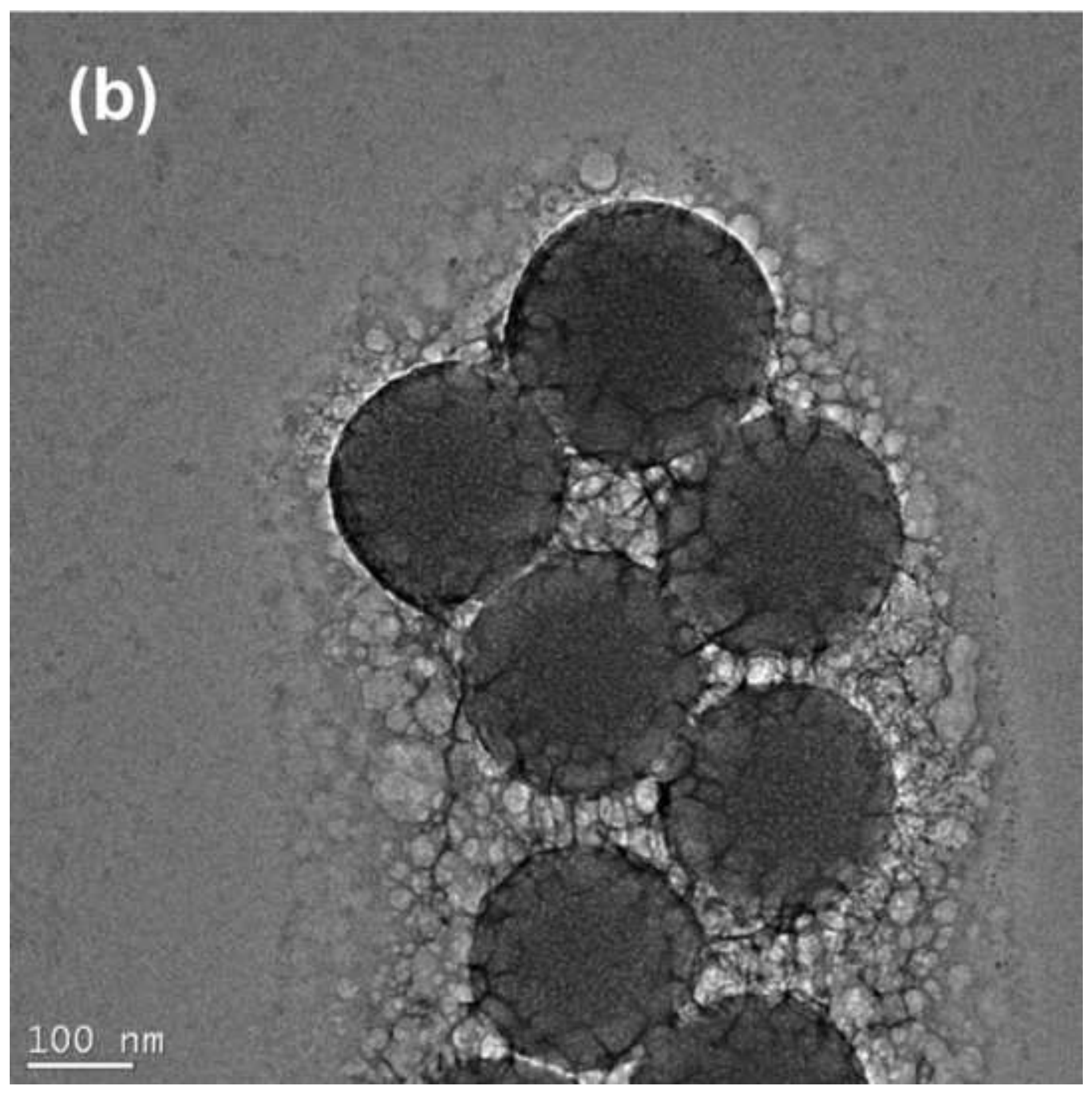

Figure $2 b$

\section{Figure 2b}

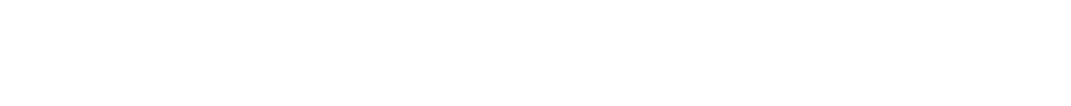

( 


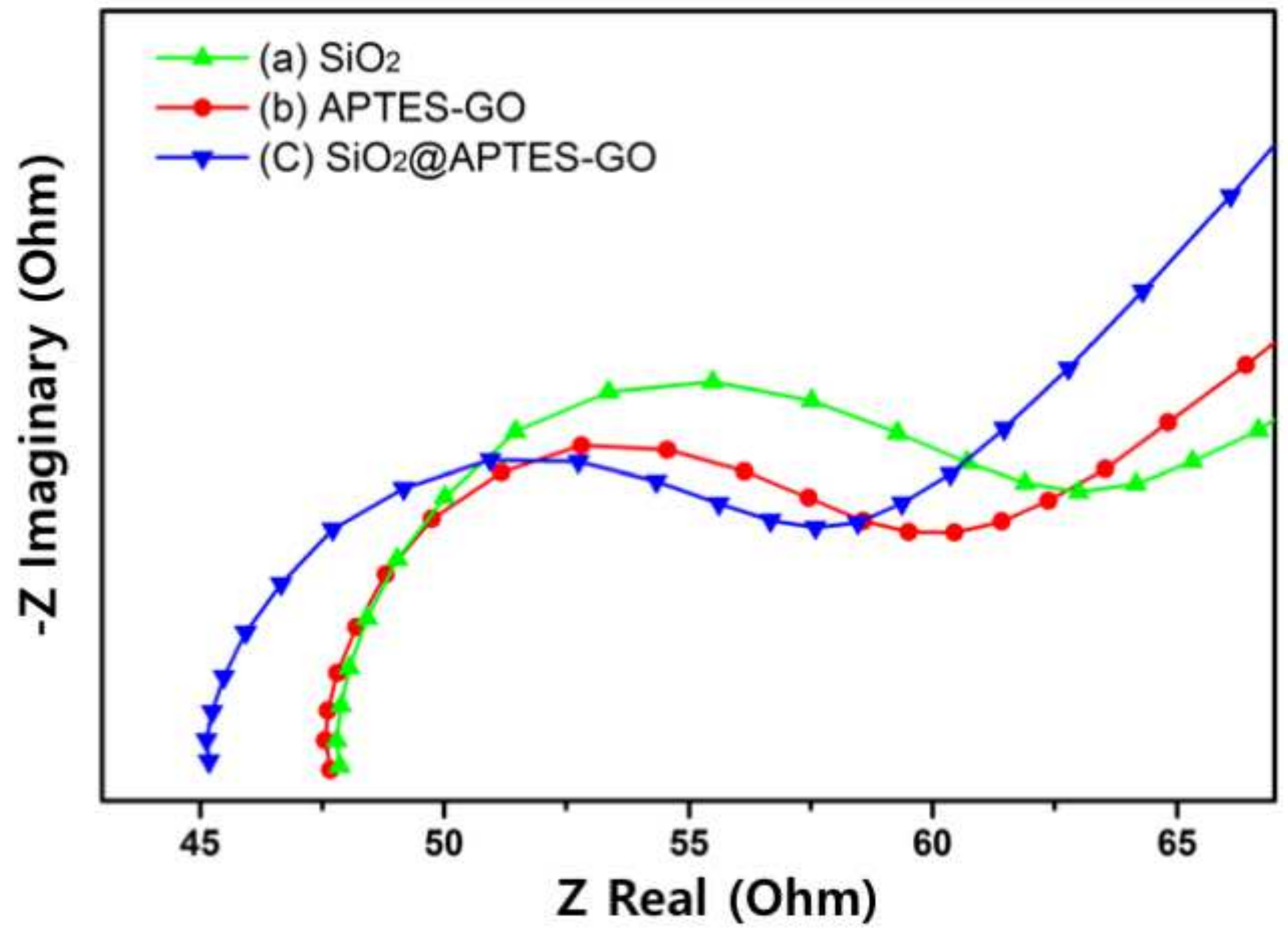




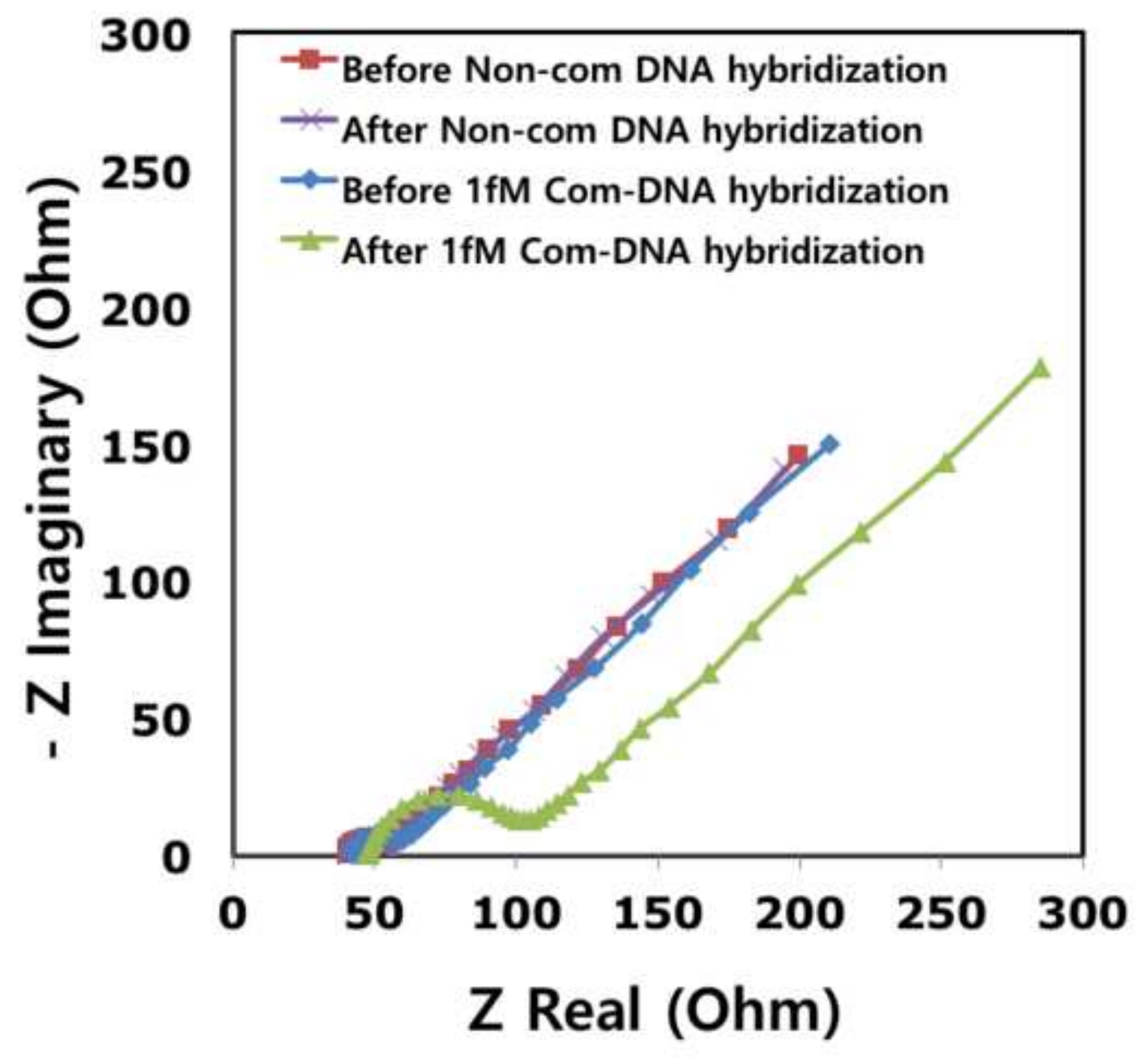

300

- Before Non-com DNA hybridization

After Non-com DNA hybridization

- After 1fM Com-DNA hybridization

Z Real (Ohm) 


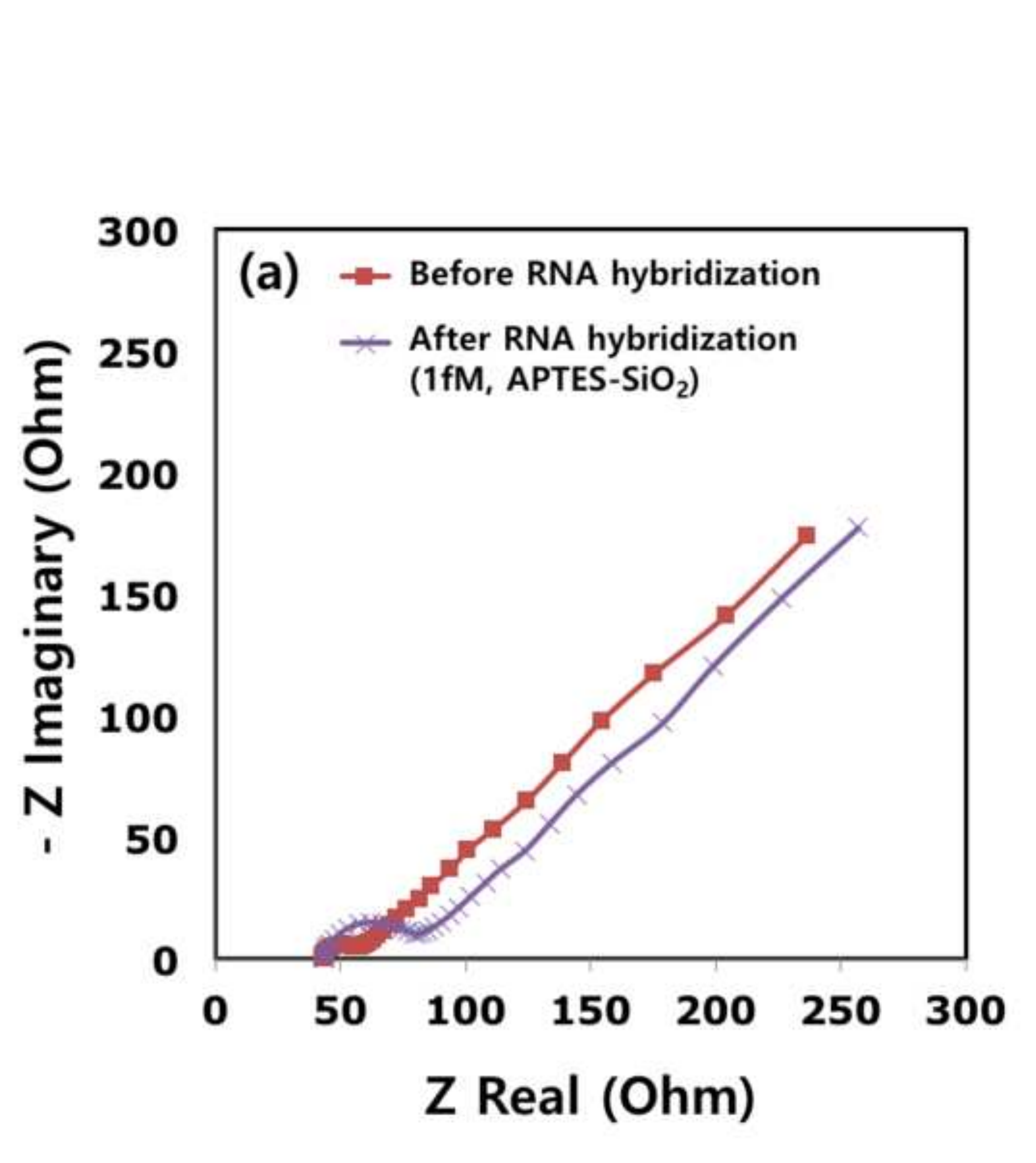

300

(a) - Before RNA hybridization After RNA hybridization (1fM, APTES-SiO ${ }_{2}$ )

.

Z Real (Ohm)

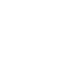




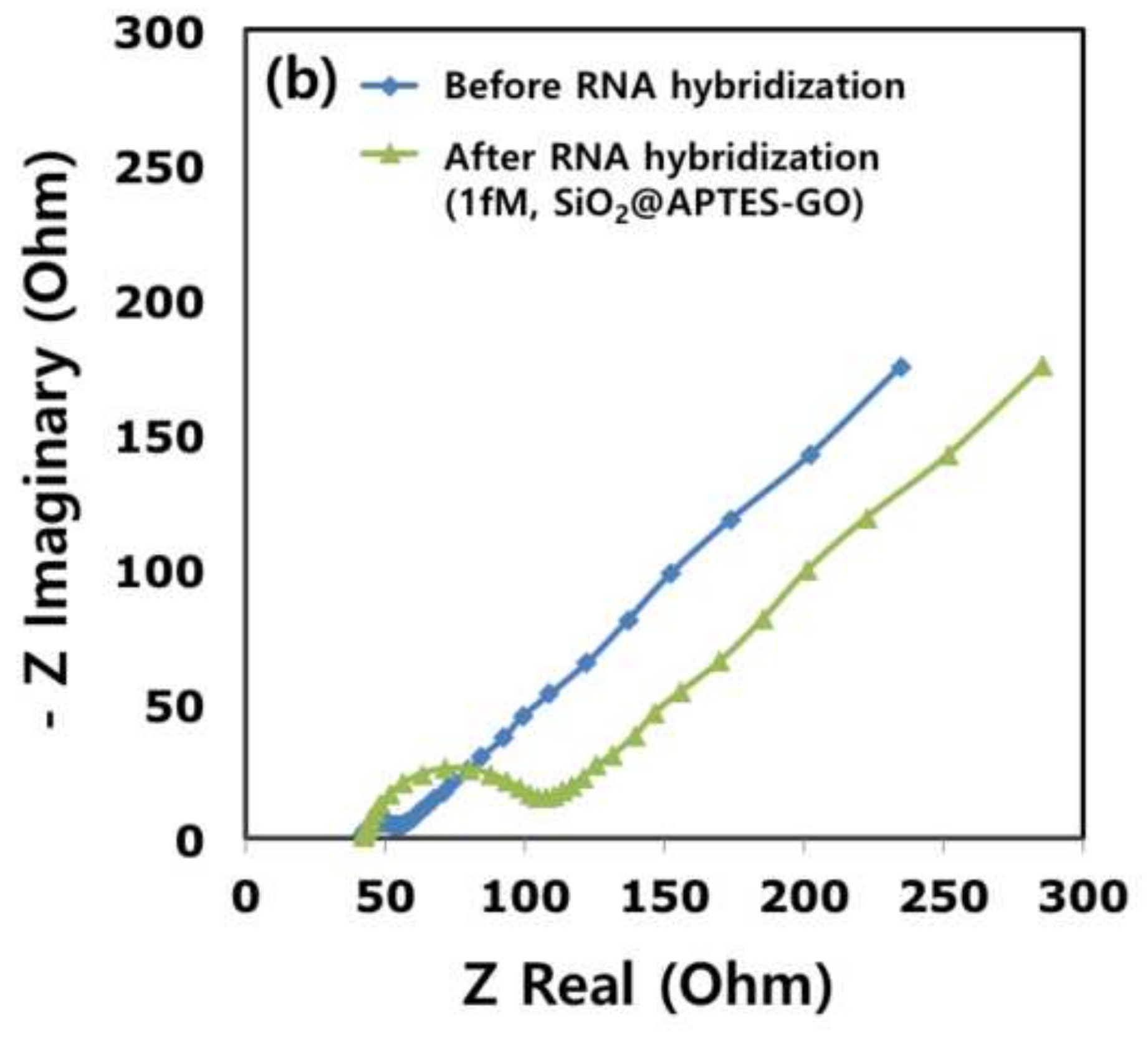

300

(b) $\rightarrow$ Before RNA hybridization

After RNA hybridization

(1fM, $\left.\mathrm{SiO}_{2} @ A P T E S-G O\right)$

\section{Z Real (Ohm)}

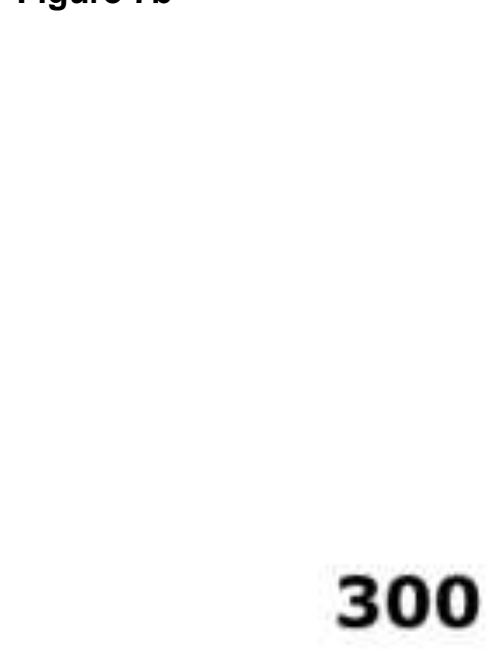

